\title{
Epidemiology of the Rhinovirus (RV) in African and Southeast Asian Children: A Case-Control Pneumonia Etiology Study
}

\author{
Vicky L. Baillie ${ }^{1,2, *(1)}$, David P. Moore ${ }^{1,2,3} \oplus$, Azwifarwi Mathunjwa ${ }^{1,2}$, Henry C. Baggett ${ }^{4,5}$, \\ Abdullah Brooks 6,7, Daniel R. Feikin ${ }^{8,9}$, Laura L. Hammitt ${ }^{8,10}$, Stephen R. C. Howie ${ }^{11,12}$, Maria Deloria Knoll ${ }^{8}{ }^{(1)}$, \\ Karen L. Kotloff ${ }^{13}$, Orin S. Levine ${ }^{8}$, Katherine L. $\mathrm{O}^{\prime}$ Brien $^{8}{ }^{8}$, Anthony G. Scott ${ }^{10,14}$, Donald M. Thea ${ }^{15}{ }^{1}$, \\ Martin Antonio ${ }^{11,16}$, Juliet O. Awori ${ }^{10}$, Amanda J. Driscoll ${ }^{8,17}$, Nicholas S. S. Fancourt ${ }^{8}$ (), Melissa M. Higdon ${ }^{8}$, \\ Ruth A. Karron ${ }^{18}$, Susan C. Morpeth 10,14,19, Justin M. Mulindwa ${ }^{20}$, David R. Murdoch ${ }^{21,22}{ }^{\mathbb{D}}$, \\ Daniel E. Park ${ }^{8,23}$ (D) Christine Prosperi ${ }^{8}$, Mohammed Ziaur Rahman ${ }^{7}$, Mustafizur Rahman ${ }^{7}$ (D), \\ Rasheed A. Salaudeen ${ }^{11,24}$, Pongpun Sawatwong ${ }^{4}$, Somwe Wa Somwe ${ }^{20}$, Samba O. Sow ${ }^{25}$, Milagritos D. Tapia ${ }^{13}$, \\ Eric A. F. Simões ${ }^{1,26}$ and Shabir A. Madhi ${ }^{1,2}$
}

\section{check for} updates

Citation: Baillie, V.L.; Moore, D.P.; Mathunjwa, A.; Baggett, H.C.; Brooks, A.; Feikin, D.R.; Hammitt, L.L.; Howie, S.R.C.; Knoll, M.D.; Kotloff, K.L.; et al. Epidemiology of the Rhinovirus (RV) in African and Southeast Asian Children: A Case-Control Pneumonia Etiology Study. Viruses 2021, 13, 1249. https://doi.org/10.3390/v13071249

Academic Editor: Gary McLean

Received: 12 May 2021

Accepted: 18 June 2021

Published: 27 June 2021

Publisher's Note: MDPI stays neutral with regard to jurisdictional claims in published maps and institutional affiliations.

Copyright: (c) 2021 by the authors. Licensee MDPI, Basel, Switzerland. This article is an open access article distributed under the terms and conditions of the Creative Commons Attribution (CC BY) license (https:// creativecommons.org/licenses/by/ $4.0 /)$.
1 South African Medical Research Council Vaccines and Infectious Diseases Analytics Research Unit, Faculty of Health Sciences, University of the Witwatersrand, Johannesburg 2050, South Africa; David.Moore@wits.ac.za (D.P.M.); azwifarwim@nicd.ac.za (A.M.); Eric.Simoes@ucdenver.edu (E.A.F.S.); madhis@rmpru.co.za (S.A.M.)

2 Department of Science and Technology/National Research Foundation: Vaccine Preventable Diseases Unit, University of the Witwatersrand, Johannesburg 1864, South Africa

3 Department of Paediatrics \& Child Health, Chris Hani Baragwanath Academic Hospital and University of the Witwatersrand, Johannesburg 1864, South Africa

4 Division of Global Health Protection, Thailand Ministry of Public Health-U.S. Centers for Disease Control and Prevention Collaboration, Nonthaburi 11000, Thailand; hfb8@cdc.gov (H.C.B.); hps5@cdc.gov (P.S.)

5 Division of Global Health Protection, Center for Global Health, Centers for Disease Control and Prevention, Atlanta, GA 30333, USA

6 Department of International Health, Johns Hopkins Bloomberg School of Public Health, Baltimore, MD 21205, USA; wbrooks3@jhu.edu

7 International Centre for Diarrhoeal Disease Research, Bangladesh (icddr,b), Dhaka and Matlab, Bangladesh; mzrahman@icddrb.org (M.Z.R.); mustafizur@icddrb.org (M.R.)

8 Department of International Health, International Vaccine Access Center, Johns Hopkins Bloomberg School of Public Health, Baltimore, MD 21205, USA; drf3217@gmail.com (D.R.F.); lhammitt@jhu.edu (L.L.H.); mknoll2@jhu.edu (M.D.K.); orin.levine@gatesfoundation.org (O.S.L.); obrienk@who.int (K.L.O.); adriscoll@som.umaryland.edu (A.J.D.); nick.fancourt@menzies.edu.au (N.S.S.F.); mhigdon@jhu.edu (M.M.H.); danpark@email.gwu.edu (D.E.P.); cprospe1@jhu.edu (C.P.)

9 Division of Viral Diseases, National Center for Immunizations and Respiratory Diseases, Centers for Disease Control and Prevention, Atlanta, GA 30333, USA

10 Kenya Medical Research Institute-Wellcome Trust Research Programme, Kilifi 80108, Kenya; anthony.scott@lshtm.ac.uk (A.G.S.); JWOtieno@kemri-wellcome.org (J.O.A.); susan.morpeth@middlemore.co.nz (S.C.M.)

11 Medical Research Council Unit at the London School of Hygiene and Tropical Medicine, Basse 273, The Gambia; stephen.howie@auckland.ac.nz (S.R.C.H.); Martin.Antonio@lshtm.ac.uk (M.A.); rsalaudeen@mrc.gm (R.A.S.)

12 Department of Paediatrics: Child \& Youth Health, University of Auckland, Park Rd, Auckland 1023, New Zealand

13 Division of Infectious Disease and Tropical Pediatrics, Department of Pediatrics, Center for Vaccine Development and Global Health, University of Maryland School of Medicine, Baltimore, MD 21205, USA; kkotloff@som.umaryland.edu (K.L.K.); MTAPIA@som.umaryland.edu (M.D.T.)

14 Department of Infectious Disease Epidemiology, London School of Hygiene \& Tropical Medicine, London WC1E 7HT, UK

15 Department of Global Health, Boston University School of Public Health, Boston, MA 02118, USA; dthea@bu.edu

16 Department of Pathogen Molecular Biology, London School of Hygiene \& Tropical Medicine, Microbiology and Infection Unit, Warwick Medical School, University of Warwick, Coventry CV4 7JJ, UK

17 Center for Vaccine Development and Global Health, University of Maryland School of Medicine, Baltimore, MD 21205, USA

18 Department of International Health, Center for Immunization Research, Johns Hopkins Bloomberg School of Public Health, Baltimore, MD 21205, USA; rkarron@jhu.edu 
19 Microbiology Laboratory, Middlemore Hospital, Counties Manukau District Health Board, Auckland 1640, New Zealand

20 Department of Paediatrics and Child Health, University Teaching Hospital, Lusaka 50110, Zambia; jmm7503@yahoo.co.uk (J.M.M.); ssow@som.umaryland.edu (S.W.S.)

21 Department of Pathology and Biomedical Sciences, University of Otago, Christchurch 8011, New Zealand; david.murdoch@otago.ac.nz

22 Microbiology Unit, Canterbury Health Laboratories, Christchurch 8140, New Zealand

23 Milken Institute School of Public Health, Department of Epidemiology, George Washington University, Washington, DC 20052, USA

24 Medical Microbiology Department, Lagos University Teaching Hospital, Lagos 100254, Nigeria

25 Centre pour le Développement des Vaccins (CVD-Mali), Bamako 198, Mali; somwewa@yahoo.com

26 Department of Pediatrics, University of Colorado School of Medicine and Center for Global Health, Colorado School of Public Health, Aurora, CO 80309, USA

* Correspondence: vicky.baillie@wits-vida.org; Tel.: +27-(11)-9834283

\begin{abstract}
Rhinovirus (RV) is commonly detected in asymptomatic children; hence, its pathogenicity during childhood pneumonia remains controversial. We evaluated RV epidemiology in HIVuninfected children hospitalized with clinical pneumonia and among community controls. PERCH was a case-control study that enrolled children (1-59 months) hospitalized with severe and very severe pneumonia per World Health Organization clinical criteria and age-frequency-matched community controls in seven countries. Nasopharyngeal/oropharyngeal swabs were collected for all participants, combined, and tested for RV and 18 other respiratory viruses using the Fast Track multiplex real-time PCR assay. RV detection was more common among cases (24\%) than controls $(21 \%)(\mathrm{aOR}=1.5,95 \% \mathrm{CI}: 1.3-1.6)$. This association was driven by the children aged 12-59 months, where $28 \%$ of cases vs. $18 \%$ of controls were RV-positive (aOR $=2.1,95 \% \mathrm{CI}: 1.8-2.5)$. Wheezing was 1.8-fold (aOR 95\%CI:1.4-2.2) more prevalent among pneumonia cases who were RV-positive vs. RV-negative. Of the RV-positive cases, $13 \%$ had a higher probability $(>75 \%)$ that RV was the cause of their pneumonia based on the PERCH integrated etiology analysis; $99 \%$ of these cases occurred in children over 12 months in Bangladesh. RV was commonly identified in both cases and controls and was significantly associated with severe pneumonia status among children over 12 months of age, particularly those in Bangladesh. RV-positive pneumonia was associated with wheezing.
\end{abstract}

Keywords: rhinovirus; epidemiology; childhood; pneumonia; PERCH

\title{
1. Introduction
}

Rhinovirus (RV) was first discovered in 1956 in individuals with mild respiratory tract infection [1]. However, since the advance in molecular diagnostic tools-namely, the polymerase chain reaction (PCR)—HRV has been recognized as one of the most prevalent respiratory viruses in children requiring hospitalization. $\mathrm{RV}$ has also been commonly detected in children with otitis media, sinusitis, asthma exacerbation, cystic fibrosis, bronchitis, and lower respiratory tract infection (LRTI) [2-12]. The role of RV in severe childhood LRTI, however, remains controversial. RV identification is ubiquitous in healthy, asymptomatic children [13], and virus shedding can persist for 10-14 days [14].

Several studies have examined RV prevalence in hospitalized children and healthy controls to determine the clinical significance of RV detection in both diseased and healthy individuals. In the majority of these studies, cases had a significantly higher prevalence of RV detected than controls [15-19]. However, these studies were not specifically designed to address the clinical epidemiology of RV and viral or bacterial coinfections in relation to disease severity $[15,17,20]$. Understanding the importance of HRV infection is critical when it comes to determining future strategies for disease treatment and prevention.

The Pneumonia Etiology for Child Health $(\mathrm{PERCH})$ study has previously reported on the overall and high-level causes of pneumonia in children [21]. In this study, we specifically focus on the clinical epidemiology of RV infection, overall and by site, and its 
interactions with other respiratory pathogens in children 1-59 months of age hospitalized with pneumonia and in community controls.

\section{Materials and Methods}

\subsection{Case and Control Definitions}

The PERCH study was undertaken in seven countries, including South Africa, Mali, Zambia, Kenya, The Gambia, Bangladesh, and Thailand from August 2011 through January 2014 (Figure 1).

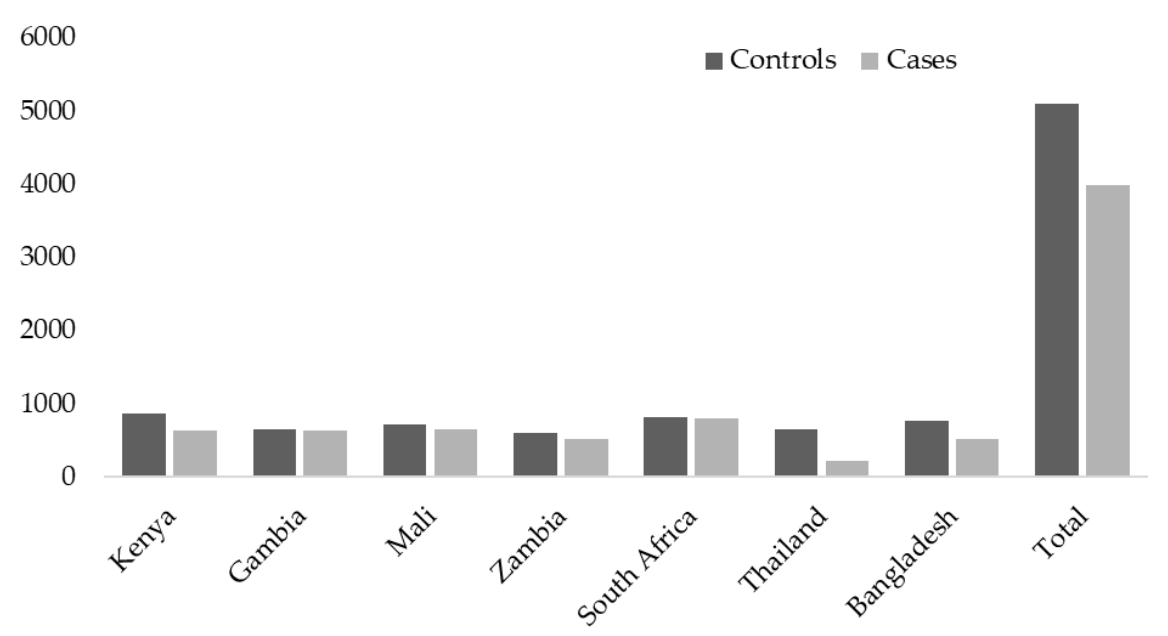

Figure 1. The number of cases and controls enrolled per country and overall.

Details on enrollment of cases and controls, sample testing, and clinical evaluation in the PERCH study have been described elsewhere [21,22]. Briefly, pneumonia cases were children aged 28 days to 59 months hospitalized with World Health Organization (WHO)defined severe or very severe pneumonia (according to the pre-2013 definitions) [23,24]. Controls were enrolled from the same communities as cases and included children without symptoms of severe or very severe pneumonia who were frequency-matched by age group and month of enrollment to the cases. For analysis, the controls were stratified into those with acute respiratory infections (ARI), defined as having (1) cough or runny nose or (2) ear discharge, wheezing or difficulty breathing, together with either a fever (temperature greater or equal to $38^{\circ} \mathrm{C}$ in the past $48 \mathrm{~h}$ ) or a sore throat, and those who were asymptomatic at the time of sampling (non-ARI).

\subsection{Specimen Collection and Laboratory Testing}

Flocked nasopharyngeal (NP) swabs (Flexible minitip, Copan ${ }^{\circledR}$, Murrieta, CA, USA) and rayon oropharyngeal (OP) swab specimens were collected from cases and controls upon enrollment. The swabs were combined in a single $3 \mathrm{~mL}$ of Universal Transport Media (Copan ${ }^{\circledR}, \mathrm{CA}, \mathrm{USA}$ )-containing vial and kept at $4-8{ }^{\circ} \mathrm{C}$ for a maximum of $24 \mathrm{~h}$, then archived at $-70{ }^{\circ} \mathrm{C}$ until tested. Total nucleic acids were extracted from the combined $\mathrm{NP} / \mathrm{OP}$ swabs using the NucleiSens EasyMag extraction system as per manufacturer's instructions (BioMerieux, Marcy l'Etoile, France) and were tested in-country by multiplex PCR for evidence of 33 pathogens (FTD Resp 33, Fast-track Diagnostics, Sliema, Malta). Standard curves were used to calculate pathogen load from PCR cycle threshold values [25].

Other investigations included blood culture on cases using the BACTEC (Becton Dickinson, Sparks, MD, USA) in South Africa, Kenya, Mali, Zambia, and The Gambia. Thailand and Bangladesh used the BacT/ Alert microbial system for blood culture (Organon Teknika, Durham, NC, USA). Induced sputum, and pleural fluid where clinically indicated, gastric aspirate, and lung aspirate (eligible cases only in The Gambia, Mali, South Africa, and Bangladesh) samples were collected and cultured using standard culture and biochemical tests. The induced sputum and pleural fluids were also tested using the FTD-33 respiratory 
panels. The FTD-33 RV results for the induced sputum showed substantial kappa concordance with the RV NP/OP results $(0.60 ; p<0.001)$. Further, the NP/OP specimens had the analytical advantage of being available for both the cases and the controls. Thus, only the NP/OP results were included in this and the previously published PERCH etiology analysis [26]. Pleural fluid specimens were also tested for pneumococcal antigen with the BinaxNow ${ }^{\circledR}$ antigen detection kit (Alere, Orlando, Florida). Microbiologically confirmed pneumococcal pneumonia (MCPP) was defined as Streptococcus pneumoniae cultured from a normally sterile fluid. In addition, a case was considered to have MCPP if the pleural fluid or lung aspirate was FTD-33 PCR positive for pneumococcus or pneumococcus antigen positive on the BinaxNow ${ }^{\circledR}$ assay.

\subsection{Statistical Analysis}

The analysis was limited to HIV-uninfected children, with the epidemiology of RV in relation to HIV infection status to be reported separately. PCR quantifications were $\log 10$ transformed. Chi-squared and Wilcoxon tests were used to analyze the demographic characteristics of cases and controls. Binary and multinomial logistic regression analyses were used to model the prevalence of RV within the study population. Age categories and site of enrolment, together with variables with an association at $p<0.2$ in the univariate analysis, were included in the multivariable models. Reverse cumulative plots were used to analyze the relationship between RV NP/OP viral loads among cases compared with controls and whether RV viral load was associated with severity of disease among cases. All statistical analysis and reverse cumulative plots were performed using STATA Version 12.1 (College Station, TX, USA), and a two-sided $p$-value $<0.05$ was considered statistically significant. Further, the PERCH integrated analysis (PIA) method, described in detail elsewhere [26-28], was used to estimate the percentage of pneumonia attributable to each pathogen, including RV. The PIA gave an estimate for both the individual- and populationlevel etiology probability distribution for each pathogen ranging from $0 \%$ to $100 \%$, with $>75 \%$ considered to be a higher probability of RV being the cause of pneumonia. The PIA assigned the probability of a pathogen being the cause of pneumonia based on the laboratory testing results and prior probability with $95 \% \mathrm{CI}$ at both the population and individual level [26].

\section{Results}

\subsection{Characteristics of Community Controls by RV Status}

$\mathrm{RV}$ was detected in $21 \%$ of community controls and was more likely to be detected in controls with ARI (25\%) than non-ARI children (20\%; aOR = 1.6, 95\%CI: $1.3-1.8)$, regardless of age group. This association was mainly driven by the Asian sites and Kenya (Supplementary Materials S1 and S2). We found no difference in NP/OP viral load between ARI controls and non-ARI controls among RV-positive participants. RV-positive controls were younger (mean age of 13.2 months) and more likely to have been born prematurely (gestational age $<37$ weeks) than those without RV infection (mean age of 16.1 months). The RV-positive controls were also more likely to have a respiratory tract infection with symptoms of rhinorrhea or cough compared with the RV-negative controls (Table 1). Thirtyeight percent of RV-positive controls were coinfected with other viruses compared with forty-seven percent of RV-negative controls. Common RV-positive co-infections included bocavirus $(\mathrm{HBoV})$, adenovirus $(\mathrm{AdV})$, and coronaviruses $(\mathrm{HCoV})$, which were also identified with similar frequency among RV-negative controls (Table 1). There was also a similar prevalence in the detection of respiratory syncytial virus (RSV), human metapneumovirus (HMPV), and parainfluenza viruses (PIV) between RV-positive and RV-negative controls, while the prevalence of co-infection with influenza virus was lower among RV-positive controls (Table 1). RV-positive controls were more likely to be co-infected with common nasopharyngeal colonizing bacteria, including M. catarrhalis, H. influenza, and S. pneumoniae, compared with the RV-negative controls. 
Table 1. Demographic and Clinical Characteristics and Respiratory Virus Co-infections among Community Controls with $(N=1056)$ and without $(N=3921)$ rhinovirus Infection, All PERCH Sites.

\begin{tabular}{|c|c|c|c|c|c|c|c|}
\hline \multirow[b]{2}{*}{ Characteristics } & \multicolumn{2}{|c|}{ Number } & \multicolumn{2}{|c|}{ Percentage } & \multirow[b]{2}{*}{$\mathrm{aOR}^{\mathrm{a}}$} & \multirow[b]{2}{*}{$95 \% \mathrm{CI}^{\mathrm{a}}$} & \multirow[b]{2}{*}{$p$-Value ${ }^{\mathrm{a}}$} \\
\hline & RV+ & RV- & RV+ & RV- & & & \\
\hline \multicolumn{8}{|l|}{ Demographic and health: } \\
\hline $12-59$ months $b$ & 409 & 1832 & 39 & 47 & 1.4 & $1.2-1.6$ & $<0.001$ \\
\hline Premature birth ${ }^{\mathrm{c}}$ & 130 & 376 & 12 & 10 & 1.3 & $1.1-1.7$ & 0.01 \\
\hline Never breast fed & 974 & 3583 & 93 & 92 & 1.2 & $0.9-1.7$ & 0.16 \\
\hline Underweight $\mathrm{d}$ & 127 & 471 & 12 & 12 & 1.03 & $0.8-1.3$ & 0.79 \\
\hline Male & 538 & 1960 & 51 & 50 & 0.95 & $0.8-1.1$ & 0.50 \\
\hline Day care attendance & 163 & 739 & 16 & 19 & 0.95 & $0.8-1.1$ & 0.50 \\
\hline Smoker in household & 392 & 1518 & 37 & 39 & 0.91 & $0.8-1.1$ & 0.15 \\
\hline \multicolumn{8}{|l|}{ Clinical: } \\
\hline $\mathrm{ARI}^{\mathrm{e}}$ & 299 & 880 & 28 & 22 & 1.6 & $1.3-1.9$ & $<0.001$ \\
\hline Rhinorrhea & 223 & 629 & 21 & 16 & 1.7 & $1.4-2.1$ & $<0.001$ \\
\hline Cough & 120 & 300 & 11 & 8 & 1.6 & $1.2-2.0$ & $<0.001$ \\
\hline Fever ${ }^{f}$ & 56 & 212 & 5 & 5 & 0.97 & $0.7-1.3$ & 0.86 \\
\hline Tachypnea $\mathrm{g}$ & 103 & 454 & 10 & 12 & 0.8 & $0.6-1.0$ & 0.05 \\
\hline Diarrhea & 13 & 82 & 1 & 2 & 0.6 & $0.3-1.04$ & 0.07 \\
\hline \multicolumn{8}{|c|}{ Respiratory viruses detected: } \\
\hline $\mathrm{AdV}$ & 134 & 458 & 13 & 12 & 1.2 & $0.98-1.5$ & 0.07 \\
\hline HMPV & 57 & 147 & 5 & 4 & 1.2 & $0.9-1.7$ & 0.26 \\
\hline $\mathrm{HBoV}$ & 138 & 521 & 13 & 13 & 1.02 & $0.8-1.3$ & 0.80 \\
\hline PIV & 68 & 246 & 6 & 6 & 0.9 & $0.7-1.2$ & 0.63 \\
\hline $\mathrm{HCoV}$ & 93 & 406 & 9 & 10 & 0.8 & $0.6-1.0$ & 0.05 \\
\hline RSV & 24 & 115 & 2 & 3 & 0.8 & $0.5-1.2$ & 0.30 \\
\hline InFV A-C & 9 & 104 & 1 & 3 & 0.3 & $0.1-0.5$ & $<0.001$ \\
\hline Any viral co-infection & 400 & 183 & 38 & 47 & 0.7 & $0.6-0.8$ & $<0.001$ \\
\hline \multicolumn{8}{|c|}{ Bacterial infections in the NP/OP: } \\
\hline H. influenzae type b & 23 & 59 & 2 & 2 & 1.6 & $0.96-2.6$ & 0.07 \\
\hline M. catarrhalis & 836 & 2857 & 79 & 73 & 1.5 & $1.2-1.7$ & $<0.001$ \\
\hline H. influenzae & 603 & 1958 & 57 & 50 & 1.4 & $1.2-1.6$ & $<0.001$ \\
\hline S. pneumoniae & 860 & 2979 & 81 & 76 & 1.4 & $1.2-1.7$ & $<0.001$ \\
\hline C. pneumoniae & 16 & 50 & 2 & 1 & 1.3 & $0.7-2.3$ & 0.39 \\
\hline M. pneumoniae & 18 & 52 & 2 & 1 & 1.3 & $0.8-2.3$ & 0.31 \\
\hline S. aureus & 135 & 542 & 13 & 14 & 0.9 & $0.7-1.1$ & 0.16 \\
\hline B. pertussis & 1 & 10 & 0 & 0 & 0.3 & $0.0-2.6$ & 0.29 \\
\hline Any bacterial co-infection & 1015 & 3687 & 96 & 94 & 1.7 & $1.2-2.3$ & 0.003 \\
\hline
\end{tabular}

Abbreviations—aOR: adjusted odds ratio; CI: confidence interval; ARI: acute respiratory infection; NP/OP: nasopharyngeal/oropharyngeal; RV: rhinovirus; RSV: respiratory syncytial virus; HMPV: human metapneumovirus; AdV: adenovirus; PIV: parainfluenza type 1-4; HBoV: human bocavirus; HCoV: human coronavirus (OC43, NL63, 229E and HKU1); and InFV: influenza virus (A, B and C). ${ }^{\text {a }} p$-values and aOR for being RV+ compared to RV - from regression models adjusted for age in months, site of enrollment, premature birth, breast feeding, smoker in the household, ARI status, and co-infecting bacteria and viruses where applicable. ${ }^{\mathrm{b}}$ The mean age and standard deviation

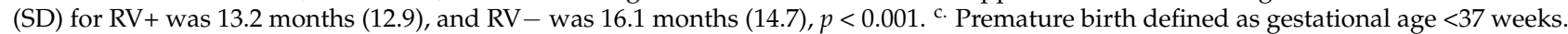
${ }^{\mathrm{d}}$ Underweight defined as weight for age $<-2 \mathrm{SD}$ of the median age-sex specific WHO reference. ${ }^{\mathrm{e}}$ Controls were considered to have ARI if they had (1) cough or runny nose or (2) one of the following signs: ear discharge, wheeze, or difficulty breathing, in the presence of sore throat or fever (temperature $\geq 38.0^{\circ} \mathrm{C}$ or reported fever in the past $48 \mathrm{~h}$ ). ${ }^{\mathrm{f}}$ Fever defined as temperature $\geq 38{ }^{\circ} \mathrm{C}$ or reported fever in the past $48 \mathrm{~h}$. ${ }^{\mathrm{g}}$ Tachypnea defined as respiratory rate $\geq 60$ breaths / minute if aged $<2$ months, respiratory rate $\geq 50$ breaths/minute if aged $2-12$ months, respiration rate $\geq 40$ breaths/minute if aged $>12$ months.

Among the RV-positive controls, those in whom RV was the only respiratory virus detected in the NP/OP swabs were younger than the children with RV together with other co-infecting viruses (Table 2). There were no other differences in demographics and in health and clinical characteristics between controls where RV was the only respiratory virus detected and RV-mixed viral infections (Table 2). The controls where RV was the only respiratory virus detected were, however, more likely to be co-infected with S. pneumoniae in the nasopharynx/oropharynx. Further, there were no differences in the RV viral load between these two groups ( 3.5 vs. $3.4 \log 10$ copies $/ \mathrm{mL} ; p=0.28$ ). 
Table 2. Demographic and Clinical Characteristics of Community Controls with rhinovirus as the Only Detected Virus (Mono-RV; $N=656$ ) and Those with rhinovirus Plus at Least One Other Respiratory Virus Detected (Mixed-RV; $N=400)$, All PERCH Sites.

\begin{tabular}{|c|c|c|c|c|c|c|c|}
\hline & \multicolumn{2}{|c|}{ Number } & \multicolumn{2}{|c|}{ Percentage } & \multirow[b]{2}{*}{$a^{O} R^{b}$} & \multirow[b]{2}{*}{$95 \% \mathrm{CI}^{\mathrm{b}}$} & \multirow[b]{2}{*}{$p$-Value ${ }^{b}$} \\
\hline & $\begin{array}{l}\text { Mono-Rv } \\
\text { Infections }\end{array}$ & $\begin{array}{l}\text { Mixed-Rv } \\
\text { Infections }^{\text {a }}\end{array}$ & $\begin{array}{l}\text { Mono-Rv } \\
\text { Infections }\end{array}$ & $\begin{array}{c}\text { Mixed-Rv } \\
\text { Infections }^{\text {a }}\end{array}$ & & & \\
\hline \multicolumn{8}{|l|}{ Demographic and health: } \\
\hline 12-59 months of age ${ }^{c}$ & 228 & 181 & 35 & 45 & 1.6 & $1.3-1.9$ & $<0.001$ \\
\hline Smoker in household & 243 & 149 & 37 & 38 & 1.2 & $0.9-1.5$ & 0.31 \\
\hline Male & 335 & 206 & 51 & 51 & 1.01 & $0.8-1.3$ & 0.92 \\
\hline Never breast fed & 52 & 25 & 8 & 6 & 1.01 & $0.6-1.8$ & 0.97 \\
\hline Underweight ${ }^{\mathrm{d}}$ & 75 & 52 & 11 & 13 & 0.98 & $0.7-1.5$ & 0.91 \\
\hline Premature birth ${ }^{\mathrm{e}}$ & 92 & 38 & 14 & 10 & 0.95 & $0.9-1.1$ & 0.44 \\
\hline Day care attendance & 86 & 77 & 13 & 19 & 0.9 & $0.7-1.2$ & 0.35 \\
\hline \multicolumn{8}{|l|}{ Clinical Features: } \\
\hline $\mathrm{ARI}^{\mathrm{f}}$ & 176 & 124 & 27 & 31 & 0.96 & $0.7-1.3$ & 0.77 \\
\hline Rhinorrhea & 132 & 733 & 20 & 17 & 1.08 & $0.9-1.2$ & 0.22 \\
\hline Fever $\mathrm{g}$ & 32 & 24 & 5 & 6 & 1.06 & $0.6-1.9$ & 0.85 \\
\hline Cough & 68 & 52 & 10 & 13 & 0.93 & $0.8-1.1$ & 0.38 \\
\hline Tachypnea ${ }^{\mathrm{h}}$ & 62 & 41 & 10 & 10 & 0.9 & $0.6-1.4$ & 0.68 \\
\hline Diarrhea & 10 & 3 & 2 & 1 & 0.8 & $0.5-1.1$ & 0.20 \\
\hline \multicolumn{8}{|c|}{ Bacterial infections in the NP/OP: } \\
\hline H. influenzae type b & 13 & 8 & 2 & 2 & 1.4 & $0.7-2.5$ & 0.32 \\
\hline S. pneumoniae & 536 & 304 & 82 & 76 & 1.4 & $1.2-1.8$ & 0.001 \\
\hline C. pneumoniae & 10 & 5 & 2 & 1 & 1.3 & $0.6-2.5$ & 0.50 \\
\hline M. catarrhalis & 502 & 296 & 77 & 74 & 1.2 & $0.95-1.4$ & 0.12 \\
\hline H. influenzae & 336 & 206 & 52 & 51 & 1.0 & $0.9-1.3$ & 0.65 \\
\hline S. aureus & 92 & 54 & 14 & 14 & 0.98 & $0.8-1.3$ & 0.89 \\
\hline B. pertussis & 1 & 1 & 0 & 0 & 0.5 & $0.1-4.3$ & 0.57 \\
\hline M. pneumoniae & 5 & 7 & 1 & 2 & 0.5 & $0.2-1.3$ & 0.16 \\
\hline Any bacterial co-infection & 628 & 370 & 96 & 92 & 2.2 & $1.5-3.2$ & $<0.001$ \\
\hline
\end{tabular}

Abbreviations—aOR: adjusted odds ratio; CI: confidence interval; RV: rhinovirus; ARI—acute respiratory infection. ${ }^{a}$ Any viral respiratory coinfection with rhinovirus and respiratory syncytial virus (A or B), human metapneumovirus, adenovirus, influenza virus (A, B or C), parainfluenza virus type 1-4, human coronavirus (OC43, NL63, 229E or HKU1). ${ }^{\mathrm{b}} p$-values and aOR for having a mono-RV infection compared with a mixed-RV infection from regression models adjusted for age in months, site of enrollment, and co-infecting bacteria where applicable. ${ }^{c}$ The mean age and standard deviation (SD) for mono-RV infections was 12.4 months (SD: 12.8 months), and mixed-RV infection was 14.5 months (SD:13.0 months; $p=0.04) .{ }^{\mathrm{d}}$ Underweight defined as weight for age $<-2$ SD of the median age-sex specific WHO reference. ${ }^{e}$ Premature birth defined as gestational age $<37$ weeks. ${ }^{\mathrm{f}}$ Controls were considered to have acute respiratory tract illness (ARI) if they had (1) cough or runny nose or (2) one of the following signs: ear discharge, wheeze, or difficulty breathing, in the presence of sore throat or fever (temperature $\geq 38.0^{\circ} \mathrm{C}$ or reported fever in the past $48 \mathrm{~h}$ ). ${ }^{\mathrm{g}}$ Fever defined as temperature $\geq 38^{\circ} \mathrm{C}$. ${ }^{\mathrm{h}}$ Tachypnea defined as respiratory rate $\geq 60$ breaths / minute if aged $<2$ months, respiratory rate $\geq 50$ breaths/minute if aged $2-12$ months, respiration rate $\geq 40$ breaths $/$ minute if aged $>12$ months.

\section{2. $R$ V infection Among Pneumonia Cases}

Of the 3870 pneumonia cases, $68 \%$ were categorized as severe and $32 \%$ as very severe. RV was detected in $24 \%$ of cases, with no difference between severe and very severe cases. Although RV-positive very severe cases had higher NP/OP RV viral load ( $3.8 \log 10$ copies $/ \mathrm{mL}$ ) than severe cases $(3.6 \log 10$ copies $/ \mathrm{mL}, p=0.01$ ), we did not identify a threshold to discriminate disease severity using reverse cumulative plot or Youden indices (Supplementary Materials S1).

RV-positive cases were significantly older than those without RV infection (mean 13.1 vs. 11.2 months), but they were similar in other demographic characteristics (Table 3). Compared with RV-negative cases, RV-positive cases were more likely to have wheezing and tachypnea. Conversely, RV-positive cases were less likely to have radiographically confirmed pneumonia (chest $\mathrm{X}$-ray with any infiltrate), to present with convulsions, and to have prolonged hospital stays ( $>3$ days). There was no association between $R V$ infection and the presence of hypoxia, mechanical ventilation, or case fatality. RV-positive cases were less likely than RV-negative cases to present with fever, alveolar consolidation on chest 
X-ray, and medically significant C-reactive protein levels (CRP $\geq 40 \mathrm{mg} / \mathrm{L}$ ). RV-positive cases were, however, more likely to have leukocytosis. RV-positive compared with RVnegative cases were less likely to be infected with RSV, influenza virus, HMPV, and PIV. The individual site evaluation is available in Supplementary Materials S3 and S4, with similar trends as observed for the overall site comparisons.

Table 3. Demographic and Clinical Characteristics and Co-Infections among Pneumonia Cases with $(N=912)$ and without $(N=2958)$ rhinovirus Infection, All PERCH Sites.

\begin{tabular}{|c|c|c|c|c|c|c|c|}
\hline & \multicolumn{2}{|c|}{ Number } & \multicolumn{2}{|c|}{ Percentage } & \multirow[b]{2}{*}{$\mathrm{aOR}^{\mathrm{a}}$} & \multirow[b]{2}{*}{$95 \% \mathrm{CI}^{\mathrm{a}}$} & \multirow[b]{2}{*}{$p$-Value } \\
\hline & RV+ & RV- & RV+ & RV- & & & \\
\hline \multicolumn{8}{|l|}{ Demographic and health: } \\
\hline $12-59$ months of age $b$ & 393 & 1025 & 43 & 35 & 0.7 & $0.6-0.9$ & $<0.001$ \\
\hline Smoker in household & 340 & 969 & 37 & 33 & 1.1 & $0.96-1.4$ & 0.12 \\
\hline Male & 539 & 1701 & 59 & 58 & 1.1 & $0.9-1.2$ & 0.49 \\
\hline Day Care attendance & 126 & 517 & 14 & 17 & 0.96 & $0.7-1.3$ & 0.77 \\
\hline Underweight $^{\mathrm{c}}$ & 277 & 916 & 30 & 31 & 0.9 & $0.8-1.1$ & 0.41 \\
\hline Premature birth ${ }^{d}$ & 87 & 328 & 10 & 11 & 0.9 & $0.7-1.1$ & 0.31 \\
\hline Never breast fed & 83 & 330 & 9 & 11 & 0.9 & $0.7-1.1$ & 0.29 \\
\hline \multicolumn{8}{|l|}{ Clinical features: } \\
\hline Wheezing & 421 & 897 & 46 & 31 & 1.8 & $1.4-2.2$ & $<0.001$ \\
\hline Tachypnea ${ }^{\mathrm{e}}$ & 785 & 2379 & 86 & 81 & 1.5 & $1.1-1.9$ & 0.01 \\
\hline Very severe pneumonia & 291 & 955 & 32 & 32 & 1.1 & $0.96-1.4$ & 0.13 \\
\hline Deaths $\mathrm{f}$ & 47 & 185 & 5 & 6 & 1.0 & $0.7-1.4$ & 0.98 \\
\hline Diarrhea & 118 & 451 & 13 & 15 & 1.0 & $0.8-1.3$ & 0.99 \\
\hline Tachycardia $\mathrm{g}$ & 439 & 1512 & 48 & 51 & 0.98 & $0.8-1.2$ & 0.83 \\
\hline Hypoxic h & 297 & 1086 & 33 & 37 & 0.98 & $0.8-1.2$ & 0.85 \\
\hline Chest $X$-ray abnormal $^{\mathrm{i}}$ & 365 & 1354 & 0 & 46 & 0.8 & $0.7-1.0$ & 0.05 \\
\hline Hospital stay $>3$ days & 453 & 1729 & 50 & 58 & 0.8 & $0.7-0.97$ & 0.02 \\
\hline Convulsions & 43 & 201 & 5 & 7 & 0.7 & $0.5-1.04$ & 0.08 \\
\hline Any symptom & 909 & 2940 & 99 & 99 & 1.9 & $0.5-6.3$ & 0.99 \\
\hline \multicolumn{8}{|c|}{ Bacterial infection markers: } \\
\hline Leukocytosis ${ }^{j}$ & 443 & 1133 & 51 & 41 & 1.3 & $1.1-1.5$ & 0.01 \\
\hline Blood culture positive $\mathrm{k}^{\mathrm{k}}$ & 29 & 107 & 3 & 4 & 0.99 & $0.6-1.5$ & 0.96 \\
\hline Fever ${ }^{1}$ & 707 & 2441 & 78 & 83 & 0.96 & $0.8-1.2$ & 0.78 \\
\hline $\mathrm{CRP}>40 \mathrm{mg} / \mathrm{mL}^{\mathrm{m}}$ & 176 & 715 & 19 & 24 & 0.9 & $0.7-1.1$ & 0.17 \\
\hline Alveolar consolidation & 156 & 657 & 18 & 24 & 0.8 & $0.7-1.1$ & 0.13 \\
\hline $\mathrm{MCPP}^{\mathrm{n}}$ & 8 & 35 & 1 & 1 & 0.8 & $0.4-1.8$ & 0.66 \\
\hline Any bacterial marker & 827 & 2701 & 91 & 91 & 0.9 & $0.7-1.2$ & 0.56 \\
\hline \multicolumn{8}{|c|}{ Respiratory viral infections in the NP/OP: } \\
\hline $\mathrm{AdV}$ & 108 & 282 & 12 & 10 & 1.3 & $0.98-1.6$ & 0.07 \\
\hline $\mathrm{HCoV}$ & 56 & 232 & 6 & 8 & 0.8 & $0.6-1.1$ & 0.14 \\
\hline HMPV & 49 & 293 & 5 & 10 & 0.5 & $0.4-0.7$ & $<0.001$ \\
\hline PIV & 76 & 435 & 8 & 15 & 0.4 & $0.3-0.5$ & $<0.001$ \\
\hline $\mathrm{HBoV}$ & 138 & 364 & 15 & 12 & 0.3 & $0.2-0.5$ & $<0.001$ \\
\hline RSV & 121 & 832 & 13 & 28 & 0.3 & $0.2-0.4$ & $<0.001$ \\
\hline InFV A-C & 5 & 173 & 1 & 6 & 0.1 & $0.02-0.2$ & $<0.001$ \\
\hline Any viral co-infection & 431 & 2192 & 47 & 74 & 0.3 & $0.25-0.34$ & $<0.001$ \\
\hline \multicolumn{8}{|c|}{ Bacterial infections in the NP/OP: } \\
\hline H. influenzae type b & 23 & 57 & 3 & 2 & 1.4 & $0.8-2.3$ & 0.19 \\
\hline B. pertussis & 8 & 23 & 1 & 1 & 1.3 & $0.6-3.0$ & 0.48 \\
\hline C. pneumoniae & 9 & 26 & 1 & 1 & 1.2 & $0.5-2.5$ & 0.73 \\
\hline M. catarrhalis & 616 & 1944 & 68 & 66 & 1.1 & $0.96-1.3$ & 0.15 \\
\hline H. influenzae & 510 & 1567 & 56 & 53 & 1.1 & $0.9-1.3$ & 0.23 \\
\hline S. pneumoniae & 661 & 2117 & 72 & 72 & 1.04 & $0.9-1.2$ & 0.66 \\
\hline S. aureus & 129 & 494 & 14 & 17 & 0.86 & $0.7-1.1$ & 0.18 \\
\hline M. pneumoniae & 12 & 45 & 1 & 2 & 0.8 & $0.4-1.6$ & 0.60 \\
\hline Any bacterial co-infection & 845 & 2714 & 93 & 92 & 0.5 & $0.8-1.5$ & 0.53 \\
\hline
\end{tabular}

Abbreviations-aOR: adjusted odds ratio; CI: confidence interval; NP/OP: nasopharyngeal/oropharyngeal; RV: rhinovirus; CRP: C-reactive 
protein; MCPP: microbiologically confirmed pneumococcal pneumonia; RSV: respiratory syncytial virus; HMPV: human metapneumovirus; AdV: adenovirus; PIV: parainfluenza type 1-4; HBoV: human bocavirus; HCoV: human coronavirus (OC43, NL63, 229E, and HKU1); and InFV: influenza virus (A, B and C). S. aureus: Staphylococcus aureus; S. pneu: Streptococcus pneumoniae; H. influenzae: Haemophilus influenzae, H. influenzae type; M. catarrhalis: Moraxella catarrahalis; B. pertussis: Bordetella pertussis; M. pneumoniae: Mycoplasma pneumoniae; C. pneumoniae: Chlamydia pneumoniae. ${ }^{a} p$-values and aOR for being RV+ compared with RV- from regression models adjusted for age in month, site of enrollment, smoker in the household, severity of pneumonia diagnosis, and co-infecting bacteria and viruses where applicable. ${ }^{b}$ The mean age and standard deviation (SD) for RV+ cases was 13.1 months (SD:12.3 months) and RV - cases (11.2 months (SD: 11.3; $p=0.50)$. ${ }^{\mathrm{C}}$ Underweight defined as weight for age $<-2 \mathrm{SD}$ of the median age-sex specific WHO reference. ${ }^{\mathrm{d}}$ Premature birth defined as gestational age $<37$ weeks. ${ }^{e}$ Tachypnea defined as respiratory rate $\geq 60$ breaths/minute if aged $<2$ months, respiratory rate $\geq 50$ breaths $/$ minute if aged 2-12 months, respiration rate $\geq 40$ breaths/minute if aged $>12$ month. ${ }^{\mathrm{f}}$ Died while in hospital. $\mathrm{g}$ Tachycardia defined as heart rate $>160$ beats per minute (bpm) if aged $<11$ months, heart rate $>150 \mathrm{bpm}$ if aged 12-35 months, heart rate $>140 \mathrm{bpm}$ if aged $36-59 \mathrm{months} .{ }^{\mathrm{h}} \mathrm{A}$ child was considered to be hypoxic if (1) a room air pulse-oximetry reading indicated oxygen saturation $<90 \%$ at the two sites at elevation (Zambia and South Africa) or $<92 \%$ at all other sites or (2) a room air oxygen saturation was not available, and the child was placed on supplemental oxygen. ${ }^{i}$ Abnormal chest $\mathrm{X}$-ray defined as radiographically confirmed end point pneumonia consolidation or any infiltrates. ${ }^{j}$ Leukocytosis defined as white blood cell count $>15,000$ cells $/ \mu \mathrm{L}$ if age $<12$ months or $>13,000$ cells $/ \mu \mathrm{L}$ if age $>12$ months. ${ }^{k}$ Blood culture positive for any non-contaminate bacteria. ${ }^{1}$ Fever defined as temperature $\geq 38{ }^{\circ} \mathrm{C}$. ${ }^{\mathrm{m}} \mathrm{CRP}$ defined as levels $\geq 40 \mathrm{mg} / \mathrm{mL}$ are considered to potentially indicate bacterial infection. ${ }^{\mathrm{n}} \mathrm{MCPP}$ defined as S. pneumoniae was cultured from a normally sterile body fluid (blood, pleural fluid, or lung aspirate), or pleural fluid or lung aspirate was PCR LytA positive.

Co-infection with at least one other respiratory virus was more common among RV-positive cases compared with RV-negative cases (Table 4). RV-positive cases without detection of other viruses (mono-RV) were older than those with co-infections, and in the multivariable analysis, adjusting for co-infecting bacteria, mono-RV cases had a higher case fatality ratio (7\%) than those with co-infections (3\%, aOR $=2.6$, aOR 95\%CI:1.2-5.5). There were other differences in demographics, clinical features, or markers of bacterial coinfections; however, the mono-RV cases were less likely to be co-infected with $\mathrm{H}$. influenzae and M. catarrhalis in the nasopharynx/oropharynx. There were no differences in RV viral load between the mono-RV infected cases ( $3.8 \log 10$ copies $/ \mathrm{mL}$ ) compared with the cases with mixed RV-viral infections ( $3.6 \log 10$ copies $/ \mathrm{mL} ; p=0.080$ ).

Of the RV-positive cases, $13 \%(N=105 / 912)$ had $>75 \%$ probability that $R V$ was the cause of their pneumonia based on the PERCH integrated etiology analysis [26]; 99\% $(\mathrm{N}=104 / 105)$ of these cases were in children over the age of 12 months from Bangladesh (Figure 2).

\subsection{Case-Control Comparison of RV Infection in Children}

In a multivariable analysis, adjusting for age category, site of enrolment and coinfecting bacteria and viruses, RV detection was more common among cases (24\%) than controls (21\%; aOR $=1.5,95 \% \mathrm{CI}: 1.3-1.6)$. RV prevalence among cases varied by age group, with the highest prevalence among those $12-59$ months of age (28\%, Figure $3 \mathrm{~B})$. Further, the prevalence of RV among the 1- to 5-month age group cases was lower than the age groupmatched controls (21\% vs. $25 \%, p=0.01)$, while higher among cases $(28 \%)$ than controls $(18 \%, \mathrm{aOR}=2.1,95 \% \mathrm{CI}: 1.8-2.5 ; p=0.03)$ in children over 12 months of age (Figure $3 \mathrm{~B}$ and Supplementary Materials Table S5). Further, RV was more likely to be detected as a mixed viral infection among cases compared with controls ( $11 \%$ vs. $8 \% ; p=0.001)$ (Figure $3 \mathrm{~A}$ and Supplementary Materials Table S5); however, by age group, this was only evident in the infants. The RV association with case status was only evident in Thailand, Bangladesh, and Kenya (Figure 3C and Supplementary Materials Table S5). However, when stratified to children $>12$ months, all sites showed a higher prevalence of RV detection in the cases vs. the controls—-though mainly in Kenya, Zambia and Bangladesh (Figure 3D-E). 
Table 4. Demographics and Clinical Characteristics of Severe and Very-Severe Pneumonia Hospitalized Cases With rhinovirus As the Only Detected Virus (Mono-RV; $N=481$ ) and Those With rhinovirus Plus at Least One Other Respiratory Virus Detected (Mixed-RV; $N=431$ ).

\begin{tabular}{|c|c|c|c|c|c|c|c|}
\hline & \multicolumn{2}{|c|}{ Number } & \multicolumn{2}{|c|}{ Percentage } & \multirow[b]{2}{*}{ aOR } & \multirow[b]{2}{*}{$\begin{array}{c}95 \% \text { CI } \\
b\end{array}$} & \multirow[b]{2}{*}{$p$-Value } \\
\hline & $\begin{array}{l}\text { Mono-RV } \\
\text { Infections }\end{array}$ & $\begin{array}{l}\text { Mixed-RV } \\
\text { Infections }^{\text {a }}\end{array}$ & $\begin{array}{l}\text { Mono-RV } \\
\text { Infections }\end{array}$ & $\begin{array}{l}\text { Mixed-RV } \\
\text { Infections }^{\text {a }}\end{array}$ & & & \\
\hline \multicolumn{8}{|l|}{ Demographic and health: } \\
\hline $12-59$ months of age ${ }^{c}$ & 231 & 162 & 48 & 38 & 0.6 & $0.5-0.8$ & $<0.001$ \\
\hline Never breast fed & 49 & 34 & 10 & 8 & 1.3 & $0.8-2.2$ & 0.28 \\
\hline Premature birth ${ }^{d}$ & 57 & 30 & 12 & 7 & 1.3 & $0.8-1.95$ & 0.28 \\
\hline Underweight ${ }^{\mathrm{e}}$ & 156 & 121 & 32 & 28 & 1.1 & $0.9-1.5$ & 0.38 \\
\hline Male & 285 & 254 & 59 & 59 & 1.1 & $0.8-1.4$ & 0.59 \\
\hline Day Care attendance & 60 & 66 & 12 & 15 & 1.1 & $0.6-1.8$ & 0.79 \\
\hline Smoker in household & 163 & 177 & 34 & 41 & 0.95 & $0.7-1.3$ & 0.76 \\
\hline \multicolumn{8}{|l|}{ Clinical features: } \\
\hline Deaths ${ }^{\mathrm{f}}$ & 33 & 14 & 7 & 3 & 2.6 & $1.2-5.5$ & 0.01 \\
\hline Convulsions & 30 & 13 & 6 & 3 & 1.98 & $0.98-4.0$ & 0.06 \\
\hline Diarrhea & 67 & 51 & 14 & 12 & 1.2 & $0.8-1.9$ & 0.31 \\
\hline Tachycardia $\mathrm{g}$ & 199 & 240 & 46 & 50 & 1.1 & $0.8-1.4$ & 0.57 \\
\hline Very severe pneumonia & 163 & 128 & 34 & 30 & 1.1 & $0.8-1.5$ & 0.71 \\
\hline Wheezing & 214 & 207 & 45 & 48 & 0.99 & $0.7-1.4$ & 0.95 \\
\hline Chest X-ray abnormal ${ }^{\mathrm{h}}$ & 188 & 177 & 39 & 41 & 0.9 & $0.7-1.2$ & 0.46 \\
\hline Hospital stay $>3$ days & 233 & 220 & 48 & 51 & 0.9 & $0.7-1.2$ & 0.45 \\
\hline Hypoxic $^{i}$ & 156 & 141 & 33 & 33 & 0.8 & $0.6-1.1$ & 0.22 \\
\hline Tachypnea $\mathrm{j}$ & 380 & 405 & 89 & 84 & 0.8 & $0.5-1.1$ & 0.18 \\
\hline Any symptom & 480 & 429 & 100 & 100 & 2.2 & $0.2-24.8$ & 0.51 \\
\hline \multicolumn{8}{|c|}{ Bacterial co-infection markers: } \\
\hline $\mathrm{MCPP}^{\mathrm{k}}$ & 6 & 2 & 1 & 0 & 4.3 & $0.8-22.4$ & 0.08 \\
\hline Blood culture positive $^{1}$ & 18 & 11 & 4 & 3 & 1.9 & $0.9-4.3$ & 0.12 \\
\hline $\mathrm{CRP} \geq 40 \mathrm{mg} / \mathrm{mL}^{\mathrm{m}}$ & 108 & 68 & 22 & 16 & 1.6 & $1.0-2.4$ & 0.04 \\
\hline Leukocytosis $^{\mathrm{n}}$ & 256 & 187 & 55 & 47 & 1.3 & $0.9-1.7$ & 0.13 \\
\hline Fever $^{\circ}$ & 369 & 338 & 77 & 78 & 1.02 & $0.7-1.4$ & 0.91 \\
\hline Alveolar consolidation & 78 & 78 & 17 & 19 & 0.9 & $0.6-1.3$ & 0.53 \\
\hline Any marker of bacterial infection & 435 & 392 & 90 & 91 & 0.8 & $0.6-1.5$ & 0.79 \\
\hline \multicolumn{8}{|l|}{ Bacterial infections in the NP/OP: } \\
\hline B. pertussis & 6 & 2 & 1 & 0 & 3.0 & $0.6-15.2$ & 0.18 \\
\hline S. aureus & 76 & 53 & 16 & 12 & 1.4 & $0.98-2.1$ & 0.06 \\
\hline C. pneumoniae & 5 & 4 & 1 & 1 & 0.99 & $0.3-3.8$ & 0.99 \\
\hline M. catarrhalis & 313 & 303 & 65 & 70 & 0.7 & $0.5-0.98$ & 0.04 \\
\hline H. influenzae & 244 & 266 & 51 & 61 & 0.6 & $0.5-0.8$ & 0.001 \\
\hline S. pneumoniae & 338 & 323 & 70 & 75 & 0.6 & $0.6-1.01$ & 0.07 \\
\hline H. influenzae type b & 9 & 14 & 2 & 3 & 0.5 & $0.2-1.3$ & 0.16 \\
\hline M. pneumoniae & 4 & 8 & 1 & 2 & 0.4 & $0.1-1.5$ & 0.18 \\
\hline Any bacterial co-infection & 440 & 405 & 91 & 94 & 0.7 & $0.4-1.2$ & 0.13 \\
\hline
\end{tabular}

Abbreviations—aOR: adjusted odds ratio; CI: confidence interval; SD: standard deviation; RV: rhinovirus; CRP: C-reactive protein; MCPP: microbiologically confirmed pneumococcal pneumonia. a Any viral respiratory coinfection with rhinovirus and respiratory syncytial virus (A or B), human metapneumovirus, adenovirus, influenza virus (A, B or C), parainfluenza virus type 1-4, human coronavirus (OC43, NL63, 229E or HKU1). ${ }^{\mathrm{b}} p$-values and aOR for having a mono-RV infection compared with a mixed-RV infection from regression models adjusted for age in month, site of enrollment, and co-infecting bacteria where applicable. ${ }^{\mathrm{c}}$ The mean age and standard deviation (SD) for mono-RV infections was 14.2 months (SD: 12.6 months), and mixed-RV infection was 11.9 months (SD:11.3 months; $p=0.005$ ). ${ }^{\mathrm{d}}$ Premature birth defined as gestational age $<37$ weeks. ${ }^{e}$ Underweight defined as weight for age $<-2 \mathrm{SD}$ of the median age-sex specific WHO reference. ${ }^{\mathrm{f}}$ Died while in hospital. $\mathrm{g}$ Tachycardia defined as heart rate $>160$ beats per minute (bpm) if aged $<11$ months, heart rate $>150 \mathrm{bpm}$ if aged 12-35 months, heart rate $>140 \mathrm{bpm}$ if aged 36-59 months. ${ }^{\mathrm{h}}$ Abnormal chest X-ray defined as radiographically confirmed end point pneumonia consolidation or any infiltrates. ${ }^{i}$ A child was considered to be hypoxic if (1) a room air pulse-oximetry reading indicated oxygen saturation $<90 \%$ at the two sites at elevation (Zambia and South Africa) or $<92 \%$ at all other sites or (2) a room air oxygen saturation was not available, and the child was placed on supplemental oxygen. ${ }^{j}$ Tachypnea defined as respiratory rate $\geq 60$ breaths/minute if aged $<2$ months, respiratory rate $\geq 50$ breaths / minute if aged $2-12$ months, respiration rate $\geq 40$ breaths/minute if aged $>12$ month. ${ }^{k}$ MCPP defined as S. pneumoniae was cultured from a normally sterile body fluid-blood, pleural fluid, or lung aspirate—or pleural fluid or lung aspirate was PCR LytA positive. ${ }^{1}$ Blood culture positive for any non-contaminate bacteria. ${ }^{\mathrm{m}}$ CRP defined as levels $\geq 40 \mathrm{mg} / \mathrm{mL}$ are considered to potentially indicate bacterial infection. ${ }^{\mathrm{n}}$ Leukocytosis defined as white blood cell count $>15,000$ cells $/ \mu \mathrm{L}$ if age $<12$ months or $>13,000$ cells $/ \mu \mathrm{L}$ if age $>12$ months. ${ }^{\circ}$ Fever defined as temperature $\geq 38^{\circ} \mathrm{C}$. 

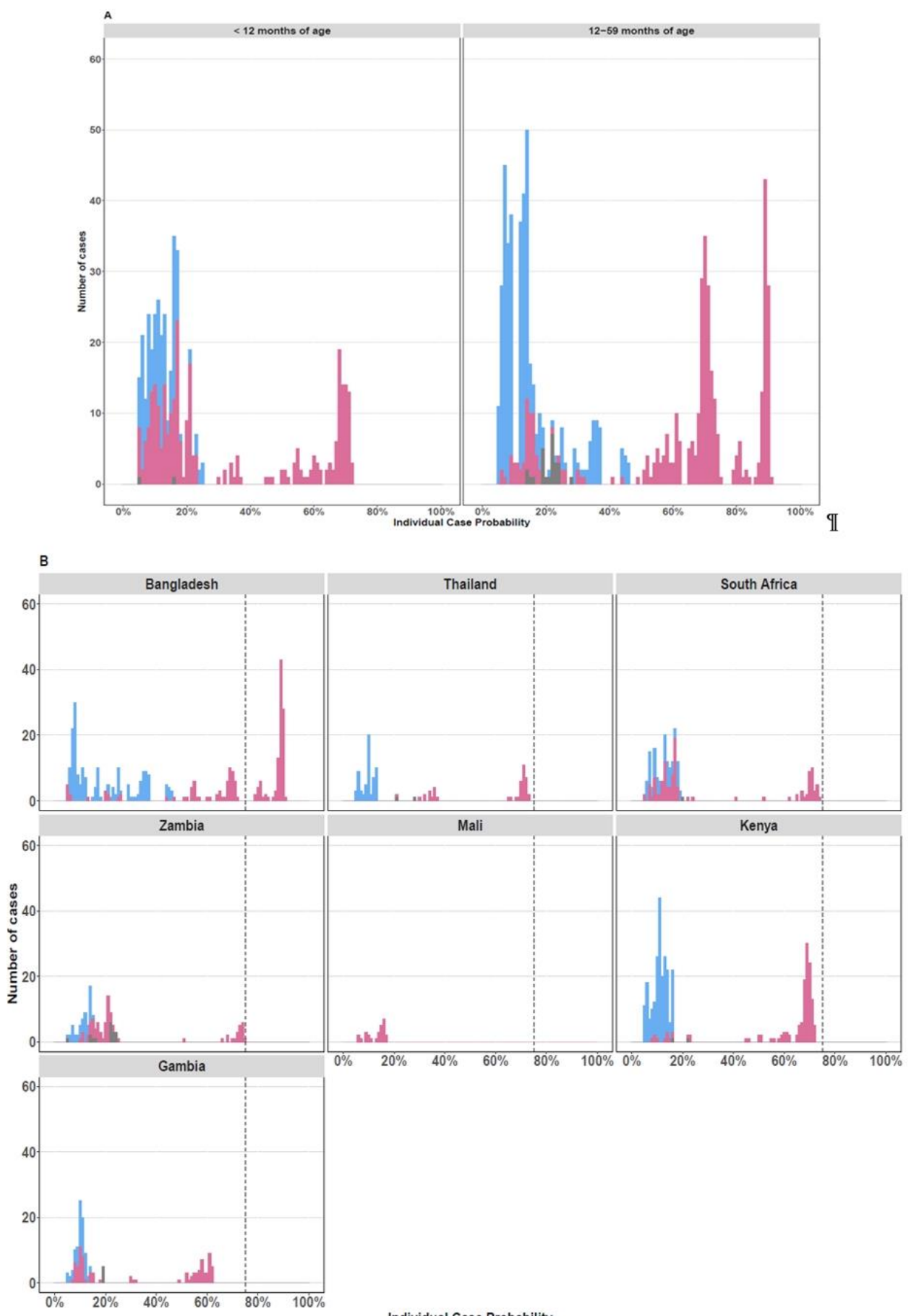

Individual Case Probability

Figure 2. Individual Case Etiological Probability of rhinovirus-Associated Pneumonia Based the PERCH Integrated Analysis, Stratified by Age Group (A) and Study Site (B). The figures display the distribution of the individual case probability that rhinovirus was the cause of pneumonia based on the PERCH integrated etiology analysis [26]. Cases with an etiologic probability $<5 \%$ for rhinovirus were excluded to scale the $y$ axis and better visualize the cases with higher probability $(>75 \%)$ of disease associated with rhinovirus. Cases testing positive for rhinovirus by nasopharyngeal/oropharyngeal RT-PCR are displayed in pink. Cases who tested negative by RT-PCR for rhinovirus are displayed in blue. Cases with missing nasopharyngeal/oropharyngeal PCR data are shown in gray. 

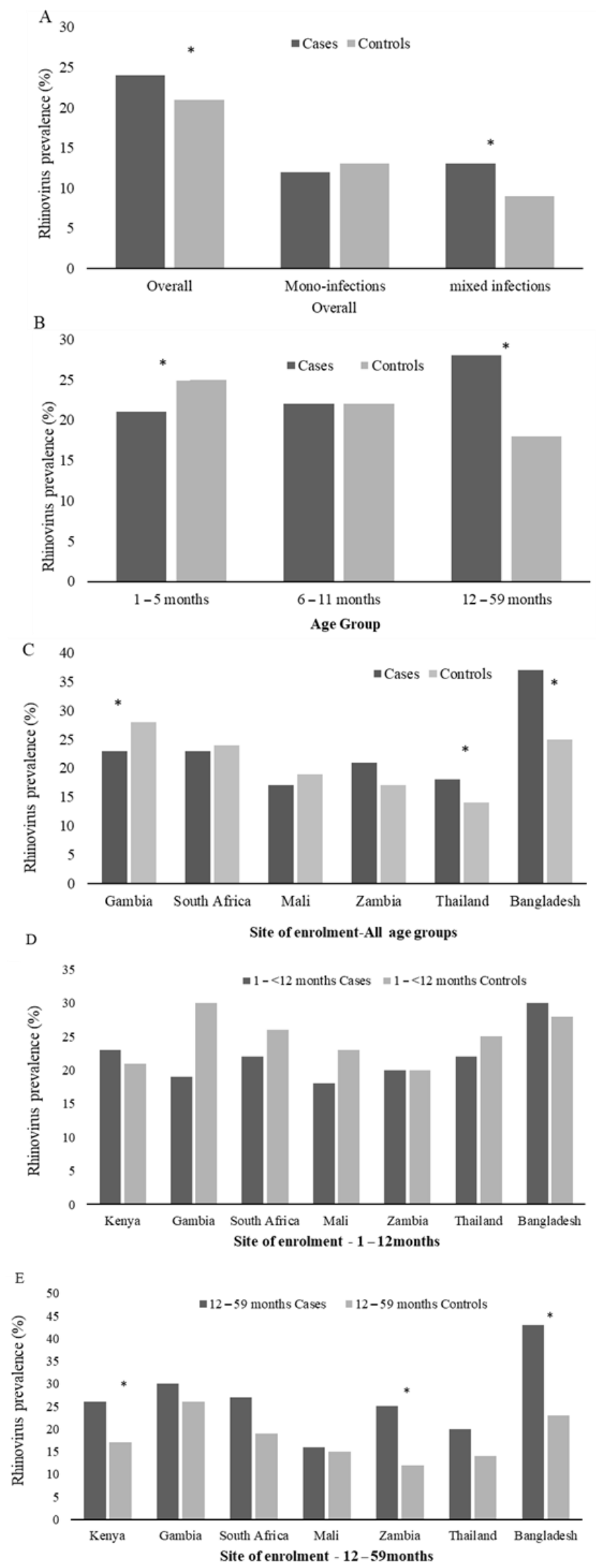

Figure 3. Prevalence of rhinovirus among Cases and Controls by PERCH overall (A), Age Group (B), and Site of enrolment (C-E). The * denotes groups where rhinovirus prevalence differs significantly (adjusted for site of enrolment and age where necessary) between cases and controls. Mono-infections 
refers to when rhinovirus was the only respiratory virus detected in the nasopharyngeal/oropharyngeal samples, and mixed infections refers to any viral co-infection with rhinovirus and RSV (A,B), HMPV, AdV, InFV (A-C), PIV type 1-4, or HCoV (OC43, NL63, 229E, and HKU1). By age group, RV detection was associated with control status in infants 1 - to < 6-months of age, and RV detection was associated with case status in children $>12-59$ months of age. By site, RV detection was associated with case status in Bangladesh and Kenya but only in children $>12$ months of age.

To identify risk factors for RV-positive pneumonia hospitalization, and because RV detection was associated with pneumonia in children $>12$ months of age (Figure $2 \mathrm{~B}$ and Supplementary Materials Table S5), we compared RV-positive cases with RV-positive controls in children 12-59 months of age (Table 5). The only difference was that the RV-positive cases were more likely than controls to be underweight and to have higher NP/OP RV viral load (3.7 vs. $3.4 \log 10$ copies/mL; $p<0.001$ ), independent of whether RV was detected as a mono- (3.8 vs. $3.5 \log 10$ copies $/ \mathrm{mL} ; p=0.002)$ or co-infection (3.3 vs. $3.3 \log 10$ copies $/ \mathrm{mL} ; p<0.001$ ) compared with the RV-positive controls. We were, however, unable to identify any RV viral load threshold that distinguished RV-positive cases from RV-infected controls either on the reverse cumulative plot or Youden index (Supplementary Materials Figure S2). Conversely, RV-positive cases were less likely to have a co-colonizing bacteria in the nasopharynx/oropharynx-in particular, S. pneumoniae and $M$ catarrhalis. Similar trends were seen when RV-positive cases were compared with RV-positive controls, regardless of age (Supplementary Materials Table S6).

Table 5. Demographic, Clinical, and Laboratory Findings of 12- to 59-month-old rhinovirus-Positive Pneumonia Cases $(N=$ 393) and Controls $(N=409)$, All PERCH Sites.

\begin{tabular}{|c|c|c|c|c|c|c|c|}
\hline & \multicolumn{2}{|c|}{ Number } & \multicolumn{2}{|c|}{ Percentage } & \multirow[b]{2}{*}{$\mathrm{aOR}^{\mathrm{a}}$} & \multirow[b]{2}{*}{$95 \% \mathrm{CI}^{\mathrm{a}}$} & \multirow[b]{2}{*}{$p$-Value ${ }^{\text {a }}$} \\
\hline & RV+ cases & $\begin{array}{c}\text { RV+ } \\
\text { controls }\end{array}$ & RV+ cases & $\begin{array}{c}\mathrm{RV}+ \\
\text { controls }\end{array}$ & & & \\
\hline \multicolumn{8}{|l|}{ Demographic and health: } \\
\hline Underweight ${ }^{b}$ & 140 & 66 & 36 & 16 & 2.8 & $2.0-4.0$ & $<0.001$ \\
\hline Male & 175 & 198 & 45 & 48 & 0.9 & $0.7-1.2$ & 0.338 \\
\hline Never breast fed & 32 & 30 & 8 & 7 & 1.5 & $0.8-2.7$ & 0.213 \\
\hline Smoker in household & 161 & 162 & 41 & 40 & 1.1 & $0.8-1.4$ & 0.673 \\
\hline Day Care attendance & 54 & 85 & 14 & 21 & 0.7 & $0.4-1.2$ & 0.216 \\
\hline Premature birth ${ }^{c}$ & 32 & 48 & 8 & 12 & 0.8 & $0.5-1.3$ & 0.428 \\
\hline RV epidemiology: & & & & & & & \\
\hline RV Co-infections $\mathrm{d}$ & 162 & 181 & 41 & 44 & 0.9 & $0.7-1.2$ & 0.526 \\
\hline RV Mono-infection ${ }^{\mathrm{e}}$ & 231 & 228 & 59 & 56 & 1.1 & $0.8-1.5$ & 0.526 \\
\hline \multicolumn{8}{|c|}{ Respiratory viral co-infections in the NP/OP: } \\
\hline RSV & 17 & 6 & 4 & 1 & 3.2 & $1.2-8.2$ & 0.018 \\
\hline PIV & 24 & 33 & 6 & 8 & 0.7 & $0.4-1.3$ & 0.245 \\
\hline $\mathrm{HBoV}$ & 70 & 68 & 18 & 17 & 1.1 & $0.8-1.7$ & 0.507 \\
\hline HMPV & 147 & 26 & 4 & 6 & 0.7 & $0.3-1.3$ & 0.243 \\
\hline AdV & 59 & 81 & 15 & 20 & 0.7 & $0.5-1.1$ & 0.105 \\
\hline InFV A-C & 2 & 1 & 1 & 0 & 2.1 & $0.2-23$ & 0.549 \\
\hline $\mathrm{HCoV}$ & 20 & 34 & 5 & 8 & 0.6 & $0.3-1.0$ & 0.069 \\
\hline \multicolumn{8}{|c|}{ Bacterial infections in the NP/OP: } \\
\hline B. pertussis & 2 & 0 & 1 & 0 & - & - & 0.149 \\
\hline H. influenzae type b & 10 & 12 & 3 & 3 & 0.8 & $0.4-2.0$ & 0.701 \\
\hline S. aureus & 41 & 34 & 10 & 8 & 1.4 & $0.8-2.2$ & 0.193 \\
\hline H. influenzae & 222 & 246 & 56 & 60 & 0.8 & $0.6-1.1$ & 0.150 \\
\hline M. pneumoniae & 7 & 12 & 2 & 3 & 0.6 & $0.2-1.5$ & 0.288 \\
\hline C. pneumoniae & 7 & 7 & 2 & 2 & 1.1 & $0.4-3.2$ & 0.874 \\
\hline S. pneumoniae & 285 & 339 & 73 & 83 & 0.5 & $0.4-0.7$ & $<0.001$ \\
\hline M. catarrhalis & 261 & 330 & 66 & 81 & 0.4 & $0.3-0.6$ & $<0.001$ \\
\hline Any bacterial co-infection & 366 & 397 & 93 & 97 & 0.4 & $0.2-0.8$ & 0.010 \\
\hline
\end{tabular}

Abbreviations_aOR: adjusted odds ratio; CI: confidence interval; SD: standard deviation; NP/OP nasopharyngeal/oropharyngeal; RV: rhinovirus; RSV: respiratory syncytial virus; HMPV: human metapneumovirus; AdV: adenovirus; PIV: parainfluenza type 1-4; HBoV: human bocavirus; HCoV: human coronavirus (OC43, NL63, 229E, and HKU1); and InFV: influenza virus (A, B and C). ${ }^{\text {a }}$-values and aOR 
for being a RV+ case compared with a RV+ control from regression models adjusted for age in month, site of enrollment, prematurity, sex, breastfeeding practices, co-infecting viruses, and bacteria where applicable. ${ }^{b}$ Underweight defined as weight for age $<-2 \mathrm{SD}$ of the median age-sex specific WHO reference. ${ }^{c}$ Premature birth defined as gestational age $<37$ weeks. ${ }^{d}$ Any viral respiratory coinfection with RSV

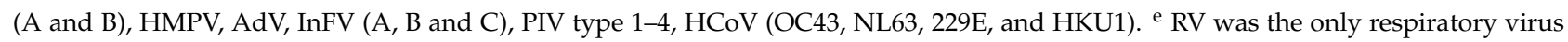
detected in the nasopharyngeal/oropharyngeal sample.

\section{Discussion}

In this large, multi-country, case-control pneumonia etiology study, it was found that children $>12-59$ months of age hospitalized with severe or very severe pneumonia were more likely to have RV detected on NP/OP swabs compared with community controls, even after adjustment for confounding variables, including the presence of other respiratory viruses. This association with case status was mainly observed in the Bangladesh sites. This association was, however, not observed among infants aged 1 to $<12$ months. Further, a high prevalence (20\%) of RV detection was detected in non-ARI community controls concordant with other studies $(10-24 \%)[9,13,15,16,18,29,30]$. This is possibly due to widespread circulation of RV coupled with prolonged shedding of RV [31]. RV detection was significantly more common among controls with ARI (25\%), once again mainly driven by the Asian sites. The association of RV with case status and ARI controls in Bangladesh children was the first real geographical difference in etiology of disease observed in the PERCH study and could potentially be linked to the increased incidence of wheezing disease and poorer air quality in Bangladesh [32]. Thus, although detection of RV in respiratory samples does not necessarily confirm causality with any concurrent illness/symptom, our results suggest a role of RV in the pathogenesis of some respiratory illness beyond the infancy period.

Notably, pneumonia cases where RV was the only respiratory virus detected in the nasopharyngeal/oropharyngeal sample in our study had higher viral loads, elevated CRP levels, and higher case fatality ratio compared with cases with RV and other viral co-infections after adjusting for site and age. This along with the negative association between RV and several other common respiratory viruses noted in our study suggests antagonism between the viruses and that perhaps when RV infections out compete other viruses, the result is a more severe infection. Regardless, the identification of RV alone among pneumonia cases is possibly of greater significance in attributing a role of RV to the pathogenesis or etiology of pneumonia among the cases. The association of RV mono-viral infections being associated with more severe disease was also reported in a previous South African study enrolling children less than 5 years of age with pneumonia [19]. Furthermore, cases had higher mean RV viral load than controls, and an association between increased viral load and more severe disease was observed among the RV-positive cases. However, we were unable to identify a specific RV nasopharyngeal density threshold to discriminate between cases and controls or among cases by severity. This association between higher $\mathrm{RV}$ viral load and more severe disease has also been described by others [33-36], where viral load correlated with illness severity.

When comparing RV-positive controls to RV-positive cases in children 12-59 months of age, the only risk factor associated with case status was malnutrition. This was, however, also a common case-control risk factor identified in the PERCH study [26]. Other study limitations included the cross-sectional study design with only a single specimen taken on enrollment into the study regardless of when symptoms started and that controls were not interviewed about disease episodes more than three days prior to enrollment. Thus, we were unable to determine the temporal association of detection of RV in relation to the onset of current or previous symptoms. Additionally, controls were not followed up to determine whether they became ill post sampling. Thus, we could not rule out the possibility they were in the incubation period of disease at the time of sampling. This was seen in a Finnish study [16] that enrolled children under the age of 15 years with acute wheezing $(N=161)$ as well as surgical controls $(N=79)$. They found that RV prevalence was $16 \%$ and $8 \%$ in the cases and controls, respectively. Although the controls were asymptomatic at the time of 
sampling, 5 of the $13 \mathrm{RV}$-positive controls developed respiratory symptoms in the following week [16]. Furthermore, our study used URT sampling as a proxy for sampling the site of infection. Direct sampling of the LRT, including lung aspirates and bronchoalveolar lavage, would provide more direct evidence on the causal pathogen of the pneumonia episode. However, these samples are invasive and difficult to perform in infants and children. The Fast Track multiplex PCR assay might have underestimated the RV prevalence, as the assay can fail to detect some RV strains [36,37]. We also cannot exclude cross-reactions between RV and enteroviruses. Genetic sequencing of positive specimens is required to better understand the contribution of RV species and enteroviruses to pneumonia etiology.

\section{Conclusions}

In conclusion, the large study size allowed us to analyze many different variables, interrogate the relevance of RV co-infections, and include controls to account for potential confounders for RV-positive disease severity and death. The study findings suggest that $\mathrm{RV}$ clinical outcomes are influenced by geographical location as well as by multiple hostspecific factors, including age, nutritional status as well as RV viral loads and the presence of viral and bacterial co-infections. It also highlights the need to test for both viral and bacterial pathogens in children hospitalized with severe pneumonia. The risk factors for infection that we have identified point the way to interventions, but they are longterm development challenges that are not easy to correct. New treatment and prevention strategies are necessary to reduce what appears to be a substantial morbidity associated with RV disease.

Supplementary Materials: The following are available online at https:/ /www.mdpi.com/article/ 10.3390/v13071249/s1, Figure S1: Reverse Cumulative Plot of RV Viral Load in the Nasopharyngeal/Oropharyngeal Sample among Very Severe and Severe Pneumonia Cases. The Viral Loads of Very Severe Cases Are Shown in Red and the Severe Cases in Purple, Figure S2: Reverse Cumulative Plot of RV Viral Load in the Nasopharyngeal/Oropharyngeal Sample among Cases and Controls. The Viral Loads of Cases Are Shown in Red and the Controls in Blue. Table S1: Demographic and Clinical Characteristics of Controls by rhinovirus Infection Status for Each African Site, Table S2: The Demographic and Clinical Characteristics of Controls by rhinovirus Infection Status for Each Southeast Asian Site Individually, Table S3: The Demographic and Clinical Characteristics of Cases by rhinovirus Infection Status for Each African Site Individually, Table S4: The Demographic and Clinical Characteristics of Cases by rhinovirus Infection Status for Each Southeast Asia Site Individually, Table S5: rhinovirus-Positive Pneumonia Cases $(N=912)$ and Controls $(N=1056)$ overall, by site of enrolment, and by age group, Table S6: Demographic, Clinical and Laboratory Findings of rhinovirus-Positive Pneumonia Cases $(N=912)$ and Controls $(N=1056)$, All PERCH Sites.

Author Contributions: Conceptualization, V.L.B., D.P.M., H.C.B., A.B., L.L.H., S.R.C.H., M.D.K., K.L.K., O.S.L., K.L.O., A.G.S., O.S.L., D.M.T., M.A., R.A.K., D.R.M., S.C.M., S.A.M. and E.A.F.S.; methodology, V.L.B., D.P.M., H.C.B., A.B., L.L.H., S.R.C.H., M.D.K., K.L.K., O.S.L., K.L.O., A.G.S., O.S.L., D.M.T., M.A., D.R.M., S.C.M., M.D.T., M.M.H., N.S.S.F., A.D; software, M.D.K., C.P., D.P.M.; formal analysis, V.L.B., S.A.M., K.L.K., D.M.T., R.A.K.; investigation, V.L.B., D.P.M., H.C.B., A.B., L.L.H., S.R.C.H., M.D.K., K.L.K., O.S.L., K.L.O., A.G.S., O.S.L., D.M.T., M.A., D.R.M., S.C.M., S.W.S., M.D.T., M.M.H., N.S.S.F., and A.J.D.; software, M.D.K., C.P. and D.E.P.; resources, A.M., D.R.F., J.O.A., J.M.M., M.Z.R., M.R., R.A.S., P.S. and S.O.S.; data curation, V.L.B., D.P.M., H.C.B., A.B., L.L.H., S.R.C.H., M.D.K., K.L.K., O.S.L., K.L.O., A.G.S., O.S.L., M.A., R.A.K., D.R.M., S.C.M., S.A.M. and E.A.F.S.; writing — original draft preparation, V.L.B.; writing—review and editing, V.L.B., K.L.K., D.M.T., R.A.K., M.D.T., S.A.M. and E.A.F.S.; supervision, S.A.M., E.A.F.S. and D.R.M.; project administration, V.L.B., D.P.M., H.C.B., A.B., L.L.H., S.R.C.H., M.D.K., O.S.L., K.L.O., A.G.S., O.S.L., D.M.T., M.A., J.M.M., D.R.M., S.C.M., S.W.S., M.D.T., S.A.M. and E.A.F.S.; funding acquisition, K.L.O., O.S.L. and S.C.M. All authors have read and agreed to the published version of the manuscript.

Funding: This work was supported by a Bill \& Melinda Gates Foundation grant to the International Vaccine Access Center, Department of International Health, Johns Hopkins Bloomberg School of Public Health (grant number 48968). 
Institutional Review Board Statement: The PERCH study was reviewed by 10 different institution review boards (IRB)-the initial overall clinical and laboratory testing protocols were reviewed by the JHSPH's IRB, after which the protocols were customized for each of the sites and reviewed by their local boards. The revised protocols and approvals for each site were then submitted to the JHSPH's IRB as amendments. This allowed for the collective ownership of the project by the PERCH executive committee as well across the sites. The ethical approvals for each of the sites are listed below:

1. Study Site: South Africa conducted by the Respiratory and Meningeal Pathogens Research Unit, Wits Health Consortium, based at Chris Hani Baragwanath Academic Hospital Wits HREC Approval number: M10M101129 Principal investigator: Prof Shabir A. Madhi

2. Study Site: Kilifi, Kenya conducted by the Kilifi-KEMRI Wellcome Trust Institute Approval number from the Kenya Medical Research Institute: KEMRI/RES/7/3/1 Oxtrec Approval number: 60-09 Principal investigator: Dr Laura Hammitt

3. Study site: Basse in The Gambia at the MRC institution Approval number from The Gambia Government/MRC joint Ethics Committee: L2010.105 Principal investigators: Dr Stephen Howie

4. Study Site: Bamako, Mali at the University of Maryland Insitution Approval number from FMPOS Ethics committee: 2011/07/FMPOS Approval number from The University of Maryland Institutional Review Board (IRB): HP00048100 Principal Investigator: Dr Karen Kotloff

5. Study Site: Lusaka, Zambia at the Boston University Institution Approval number from the Blue Panel IRB: HP-29860 Approval from the ERES Converge IRB: 2010-Dec-001 Principal Investigator: Dr Donald Thea

6. Study site: Dhaka, Bangladesh at the ICDDR and JHSPH institution Approval number from ICDDR,B Ethics Review Committee: PR-11012 Principal Investigators: Dr Abdullah Brooks

7. Study site: Sa Kaeo and Nakhon Phanom in Thailand at the CDC-Thailand Approval number from the Ethical Review Committee for Research in Human Subjects-Ministry of Public Health, Thailand: 17/2554 Principal Investigators: Dr Pasakorn Akarasewi Approval to conduct the clinical and molecular subtyping analysis of HRV in the PERCH project was obtained from the PERCH executive committee on the 18 June 2014 and ethical approval was granted by the University of the Witwatersrand Human Rights and Ethics Board (HREC number: M140906).

Informed Consent Statement: Informed consent was obtained from all subjects involved in the study.

Data Availability Statement: All data are available at https://clinepidb.org/ce/app (accessed 12 May 2021).

Acknowledgments: We acknowledge the work of all PERCH contributors who were involved in data collection at the local sites and central laboratories, members of the PERCH Chest Radiograph Reading Panel, and Shalika Jayawardena and Rose Watt from Canterbury Health Laboratories. Finally, we offer sincere thanks to the patients and families who participated in the study.

Conflicts of Interest: S.A.M. has received honoraria for advisory board participation from Bill \& Melinda Gates Foundation, Pfizer, Medimmune, and Novartis and institutional grants from GSK, Novartis, Pfizer, Minervax, and Bill \& Melinda Gates Foundation and has served on speakers' bureaus for Sanofi Pasteur and GSK. M.D.K. has received funding for consultation from Merck, Pfizer, and Novartis and grant funding from Merck. C.P. has received grant funding from Merck. K.L.O. has received grant funding from GlaxoSmithKline and Pfizer and participates on technical advisory boards for Merck, Sanofi-Pasteur, PATH, Affinivax, and ClearPath. K.L.K. has received grant funding from Merck Sharp \& Dohme. W.A.B. reported funding from Sanofi, PATH, and Bill \& Melinda Gates Foundation (BMGF) and contributed to contemporaneous studies from Serum Institute of India, LTD, Roche, and Sanofi. All other authors: No reported conflicts. Conflicts that the editors consider relevant to the content of the manuscript have been disclosed.

\section{References}

1. Price, W.H. The isolation of a new virus associated with respiratory clinical disease in humans. Proc. Natl. Acad. Sci. USA 1956, 42, 892-896. [CrossRef]

2. Papadopoulos, N.G. Do rhinoviruses cause pneumonia in children? Paediatr. Respir. Rev. 2004, 5, S191-S195. [CrossRef]

3. Louie, J.K.; Roy-Burman, A.; Guardia-LaBar, L.; Boston, E.J.; Kiang, D.; Padilla, T.; Yagi, S.; Messenger, S.; Petru, A.M.; Glaser, C.A.; et al. Rhinovirus associated with severe lower respiratory tract infections in children. Pediatr. Infect. Dis. J. 2009, 28, 337-339. [CrossRef] [PubMed] 
4. Esposito, S.; Daleno, C.; Prunotto, G.; Scala, A.; Tagliabue, C.; Borzani, I.; Fossali, E.; Pelucchi, C.; Principi, N. Impact of viral infections in children with community-acquired pneumonia: Results of a study of 17 respiratory viruses. Influenza Other Respir. Viruses 2012, 7, 18-26. [CrossRef] [PubMed]

5. Piotrowska, Z.; Vázquez, M.; Shapiro, E.D.; Weibel, C.; Ferguson, D.; Landry, M.L.; Kahn, J.S. Rhinoviruses are a major cause of wheezing and hospitalization in children less than 2 years of age. Pediatr. Infect. Dis. J. 2009, 28, 25-29. [CrossRef]

6. Renwick, N.; Schweiger, B.; Kapoor, V.; Liu, Z.; Villari, J.; Bullmann, R.; Miething, R.; Briese, T.; Lipkin, W.I. A recently identified rhinovirus genotype is associated with severe respirato-ry-tract infection in children in Germany. J. Infect. Dis. 2007, 196, 1754-1760. [CrossRef] [PubMed]

7. Wisdom, A.; Leitch, E.M.; Gaunt, E.; Harvala, H.; Simmonds, P. Screening respiratory samples for detection of human rhinoviruses (HRVs) and enteroviruses: Comprehensive VP4-VP2 typing reveals high incidence and genetic diversity of HRV species C. J. Clin. Microbiol. 2009, 47, 3958-3967. [CrossRef]

8. E Smuts, H.; Workman, L.J.; Zar, H.J. Human rhinovirus infection in young African children with acute wheezing. BMC Infect. Dis. 2011, 11, 65. [CrossRef] [PubMed]

9. Johnston, S.L.; Sanderson, G.; Pattemore, P.K.; Smith, S.; Bardin, P.G.; Bruce, C.B.; Lambden, P.R.; Tyrrell, D.A.; Holgate, S.T. Use of polymerase chain reaction for diagnosis of picornavirus infection in subjects with and without respiratory symptoms. J. Clin. Microbiol. 1993, 31, 111-117. [CrossRef] [PubMed]

10. Khetsuriani, N.; Lu, X.; Teague, W.G.; Kazerouni, N.; Anderson, L.J.; Erdman, D.D. Novel human rhinoviruses and exacerbation of asthma in children1. Emerg. Infect. Dis. 2008, 14, 1793-1796. [CrossRef]

11. Arden, K.E.; Mackay, I.M. Newly identified human rhinoviruses: Molecular methods heat up the cold viruses. Rev. Med. Virol. 2010, 20, 156-176. [CrossRef] [PubMed]

12. Hansbro, N.G.; Horvat, J.C.; Wark, P.; Hansbro, P. Understanding the mechanisms of viral induced asthma: New therapeutic directions. Pharmacol. Ther. 2008, 117, 313-353. [CrossRef] [PubMed]

13. Jartti, T.; Jartti, L.; Peltola, V.; Waris, M.; Ruuskanen, O. Identification of respiratory viruses in asymptomatic subjects: Asymptomatic respiratory viral infections. Pediatric Infect. Dis. J. 2008, 27, 1103-1107. [CrossRef] [PubMed]

14. Mackay, I.M. Human rhinoviruses: The cold wars resume. J. Clin. Virol. 2008, 42, 297-320. [CrossRef] [PubMed]

15. Calvo, C.; Casas, I.; Garcia-Garcia, M.L.; Pozo, F.; Reyes, N.; Cruz, N.; García-Cuenllas, L.; Pérez-Breña, P. Role of Rhinovirus c respiratory infections in sick and healthy children in Spain. Pediatr. Infect. Dis. J. 2010, 29, 717-720. [CrossRef]

16. Jartti, T.; Lehtinen, P.; Vuorinen, T.; Koskenvuo, M.; Ruuskanen, O. Persistence of rhinovirus and enterovirus RNA after acute respiratory illness in children. J. Med. Virol. 2004, 72, 695-699. [CrossRef]

17. Fry, A.M.; Lu, X.; Olsen, S.J.; Chittaganpitch, M.; Sawatwong, P.; Chantra, S.; Baggett, H.C.; Erdman, D. Human rhinovirus infections in rural thailand: Epidemiological evidence for rhinovirus as both pathogen and bystander. PLoS ONE 2011, 6, e17780. [CrossRef]

18. Iwane, M.K.; Prill, M.M.; Lu, X.; Miller, E.K.; Edwards, K.M.; Hall, C.B.; Griffin, M.R.; Staat, M.A.; Anderson, L.J.; Williams, J.; et al. Human Rhinovirus Species Associated with Hospitalizations for Acute Respiratory Illness in Young US Children. J. Infect. Dis. 2011, 204, 1702-1710. [CrossRef]

19. Venter, M.; Lassaunière, R.; Kresfelder, T.L.; Westerberg, Y.; Visser, A. Contribution of common and recently described respira-tory viruses to annual hospitalizations in children in South Africa. J. Med. Virol. 2011, 83, 1458-1468. [CrossRef]

20. Baillie, V.L.; Olwagen, C.P.; Madhi, S.A. Review on clinical and molecular epidemiology of human rhinovirus-associated lower respiratory tract infections in African and southeast Asian children. Pediatr. Infect. Dis. J. 2018, 37, e185-e194. [CrossRef]

21. O’Brien, K.L.; Baggett, H.C.; Brooks, W.A.; Feikin, D.R.; Hammitt, L.L.; Higdon, M.M.; Howie, S.R.; Knoll, M.D.; Kotloff, K.L.; Levine, O.S.; et al. Causes of severe pneumonia requiring hospital admission in children without HIV infection from Africa and Asia: The PERCH multi-country case-control study. Lancet 2019, 394, 757-779. [CrossRef]

22. World Health Organization. Acute Respiratory Infections in Children: Case Management in Small Hospitals in Developing Countries, a Manual for Doctors and Other Senior Health Workers; World Health Organization: Geneva, Switzerland, 1990.

23. World Health Organization. Technical Bases for the WHO Recommendations on the Management of Pneumonia in Children at First-Level Health Facilities; World Health Organization: Geneva, Switzerland, 1991.

24. Murdoch, D.R.; O'Brien, K.; Driscoll, A.J.; Karron, R.A.; Bhat, N. The Pneumonia Methods Working Group; Perch core the perch core team laboratory methods for determining pneumonia etiology in children. Clin. Infect. Dis. 2012, 54, S146-S152. [CrossRef] [PubMed]

25. Deloria-Knoll, M.; Feikin, D.R.; Scott, J.A.G.; O’Brien, K.L.; DeLuca, A.N.; Driscoll, A.J.; Levine, O.S.; Pneumonia Methods Working Group. Identification and selection of cases and controls in the Pneumonia Eti-ology Research for Child Health project. Clin. Infect. Dis. 2012, 54 (Suppl. S2), S117-S123. [CrossRef] [PubMed]

26. Wu, Z.; Deloria-Knoll, M.; Zeger, S.L. Nested partially latent class models for dependent binary data; estimating disease etiol-ogy. Biostatistics 2016, 18, 200-213.

27. Deloria Knoll, M.; Fu, W.; Shi, Q.; Prosperi, C.; Wu, Z.; Hammitt, L.L.; Feikin, D.R.; Baggett, H.C.; Howie, S.R.; Scott, J.A.G.; et al. Bayesian estimation of pneumonia etiology: Epidemiologic considerations and applications to the pneumonia etiology research for child health study. Clin. Infect. Dis. 2017, 64 (Suppl. S3), S213-S227. [CrossRef]

28. Principi, N.; Zampiero, A.; Gambino, M.; Scala, A.; Senatore, L.; Lelii, M.; Ascolese, B.; Pelucchi, C.; Esposito, S. Prospective evaluation of rhinovirus infection in healthy young children. J. Clin. Virol. 2015, 66, 83-89. [CrossRef] [PubMed] 
29. Pretorius, M.; Tempia, S.; Treurnicht, F.K.; Walaza, S.; Cohen, A.L.; Moyes, J.; Hellferscee, O.; Variava, E.; Dawood, H.; Chhagan, M.; et al. Genetic diversity and molecular epidemiology of human rhinoviruses in South Africa. Influenza Other Respir. Viruses 2014, 8, 567-573. [CrossRef]

30. Loeffelholz, M.J.; Trujillo, R.; Pyles, R.B.; Miller, A.L.; Alvarez-Fernandez, P.; Pong, D.L.; Chonmaitree, T. Duration of Rhinovirus Shedding in the Upper Respiratory Tract in the First Year of Life. Pediatrics 2014, 134, 1144-1150. [CrossRef] [PubMed]

31. Pfister, A.M. Air Pollution: Mass Killer in Bangladesh. 2001. Available online: https://www.who.int/docstore/peh/ceh/articles/ airpollution.htm (accessed on 11 May 2020).

32. Esposito, S.; Daleno, C.; Scala, A.; Castellazzi, L.; Terranova, L.; Papa, S.S.; Longo, M.R.; Pelucchi, C.; Principi, N. Impact of rhinovirus nasopharyngeal viral load and viremia on severity of respiratory infections in children. Eur. J. Clin. Microbiol. Infect. Dis. 2014, 33, 41-48. [CrossRef]

33. Bruning, A.H.; Thomas, X.V.; van der Linden, L.; Wildenbeest, J.G.; Minnaar, R.P.; Jansen, R.R.; de Jong, M.D.; Sterk, P.J.; van der Schee, M.P.; Wolthers, K.C.; et al. Clinical, virological and epidemiological characteristics of rhinovirus infections in early childhood: A comparison between non-hospitalised and hospitalised children. J. Clin. Virol. 2015, 73, 120-126. [CrossRef] [PubMed]

34. Takeyama, A.; Hashimoto, K.; Sato, M.; Sato, T.; Kanno, S.; Takano, K.; Ito, M.; Katayose, M.; Nishimura, H.; Kawasaki, Y.; et al. Rhinovirus load and disease severity in children with lower respiratory tract in-fections. J. Med. Virol. 2012, 84, 1135-1142. [CrossRef] [PubMed]

35. Ambrosioni, J.; Bridevaux, P.-O.; Aubert, J.-D.; Soccal, P.; Wagner, G.; Kaiser, L. Role of rhinovirus load in the upper respiratory tract and severity of symptoms in lung transplant recipients. J. Clin. Virol. 2015, 64, 1-5. [CrossRef] [PubMed]

36. Sakthivel, S.K.; Whitaker, B.; Lu, X.; Oliveira, D.B.; Stockman, L.J.; Kamili, S.; Oberste, M.S.; Erdman, D.D. Comparison of fast-track diagnostics respiratory pathogens multiplex real-time RT-PCR assay with in-house singleplex assays for comprehensive detection of human respiratory viruses. J. Virol. Methods 2012, 185, 259-266. [CrossRef]

37. Baillie, V.L.; Moore, D.P.; Mathunjwa, A.; Morailane, P.; Simões, E.A.; Madhi, S.A. Molecular subtyping of human rhinovirus in chil-dren from three sub-Saharan African countries. J. Clin. Microbiol. 2019, 57, e00723-19. [CrossRef] [PubMed] 